Article

\title{
Antileishmanial Activity of Dimeric Flavonoids Isolated from Arrabidaea brachypoda
}

\author{
Vinícius P. C. Rocha ${ }^{1}{ }^{\circledR}$, Cláudia Quintino da Rocha ${ }^{2}{ }^{\mathbb{D}}$, Emerson Ferreira Queiroz ${ }^{3}$, \\ Laurence Marcourt $^{3}$, Wagner Vilegas ${ }^{4}$, Gabriela B. Grimaldi ${ }^{1}{ }^{1}$, Pascal Furrer ${ }^{3}$, Éric Allémann ${ }^{3}$, \\ Jean-Luc Wolfender ${ }^{3}$ iD and Milena B. P. Soares ${ }^{1, *}$ \\ 1 Laboratório de Engenharia Tecidual e Imunofarmacologia, Instituto Gonçalo Moniz, Fundação Oswaldo \\ Cruz (Fiocruz), Avenida Waldemar Falcão, 121, Candeal-Salvador-BA 40296-710, Brazil; \\ viny_rocha@hotmail.com (V.P.C.R.); gabrielagrimaldi16.1@bahiana.edu.br (G.B.G.) \\ 2 Departamento de Química, Universidade Federal do Maranhão, São Luiz 65080-805, MA, Brazil; \\ claudiarocha3@yahoo.com.br \\ 3 School of Pharmaceutical Sciences, EPGL, University of Geneva, University of Lausanne, CMU, \\ 1, Rue Michel Servet, 1211 Geneva, Switzerland; emerson.ferreira@unige.ch (E.F.Q.); \\ laurence.marcourt@unige.ch (L.M.); pascal.furrer@unige.ch (P.F.); \\ eric.allemann@unige.ch (E.A.); jean-luc.wolfender@unige.ch (J.-L.W.) \\ 4 UNESP-Campus Experimental do Litoral Paulista, Praça Infante Dom Henrique s $/ \mathrm{n}^{\circ}$, Parque Bitaru, \\ São Vicente-SP 11330-900, Brazil; vilegasw@clp.unesp.br \\ * Correspondence: milena@bahia.fiocruz.br; Tel.: +55-71-3176-2292
}

Academic Editor: Thomas J. Schmidt

Received: 20 November 2018; Accepted: 19 December 2018; Published: 20 December 2018

\begin{abstract}
Leishmaniasis are diseases caused by parasites belonging to Leishmania genus. The treatment with pentavalent antimonials present high toxicity. Secondary line drugs, such as amphotericin B and miltefosine also have a narrow therapeutic index. Therefore, there is an urgent need to develop new drugs to treat leishmaniasis. Here, we present the in vitro anti-leishmanial activity of unusual dimeric flavonoids purified from Arrabidaea brachypoda. Three compounds were tested against Leishmana sp. Compound 2 was the most active against promastigotes. Quantifying the in vitro infected macrophages revealed that compound 2 was also the most active against intracellular amastigotes of L. amazonensis, without displaying host cell toxicity. Drug combinations presented an additive effect, suggesting the absence of interaction between amphotericin B and compound 2 . Amastigotes treated with compound 2 demonstrated alterations in the Golgi and accumulation of vesicles inside the flagellar pocket. Compound 2-treated amastigotes presented a high accumulation of cytoplasmic vesicles and a myelin-like structure. When administered in L. amazonensis-infected mice, neither the oral nor the topical treatments were effective against the parasite. Based on the high in vitro activity, dimeric flavonoids can be used as a lead structure for the development of new molecules that could be useful for structure-active studies against Leishmania.
\end{abstract}

Keywords: Leishmania; flavonoids; high content; Arrabidaea brachypoda

\section{Introduction}

Leishmaniasis is a complex of diseases caused by protozoan parasites belonging to the genus Leishmania and transmitted by the bite of the female sand fly vector. The disease is endemic in 98 countries. Around 58,000 cases of visceral leishmaniasis and 220,000 cases of the cutaneous disease are officially reported per year worldwide [1]. The first-line treatment is performed with the pentavalent antimonials. Although still used, this chemotherapy presents several limitations, such as serious side effects, including patient death, prolonged course of treatment and emergence of drug resistance. 
Second-line drugs such as amphotericin B (AMB) and miltefosine can be used. However, similar to antimonials, these medicines are also associated with serious side effects, high cost and resistance [2]. Leishmaniasis represents a large social and economic burden. Due to the limitations of the current chemotherapy available, there is an urgent need to discover new drugs for the treatment of these devastating and neglected diseases.

Arrabidaea brachypoda (D.C.) is a native plant in Brazil, widely distributed throughout different biomes, belonging to the Bignoniaceae family, which encompasses 120 genera and approximately 800 species of plants, which constitute important components of neotropical forests. Phytochemical studies indicated that the Arrabidaeae genus is a source of C-glucosylxanthones, phenylpropanoids, flavonoids, anthocyanidins, allantoins and triterpenes [3,4]. In traditional medicine, species of this genus are used for different therapeutic purposes, such as astringent, anti-inflammatory, antimicrobial, antitumor and healing [5].

In Brazil, Arrabidaea brachypoda known as "cervejinha do campo", is popularly used to treat kidney stones and arthritis, and has presented significant anti-inflammatory activity in experimental models [6,7]. Moreover, the anti-Plasmodium falciparum activity of other structurally related benzopyrano[4,3-b]benzopyran has been reported [8]. We have recently demonstrated the in vitro anti-Trypanosoma cruzi activity of the aqueous ethanol extract of the roots from A. brachypoda and its $\mathrm{CH}_{2} \mathrm{Cl}_{2}$ fraction. A follow-up investigation of the constituents from the $\mathrm{CH}_{2} \mathrm{Cl}_{2}$ fraction revealed the presence of three new dimeric flavonoids with different anti-T. cruzi activity in vitro and in an in vivo model of acute Chagas disease [7]. Based on the potential of the three dimeric flavonoids from A. brachypoda as anti-T. cruzi compounds, we investigated the anti-Leishmania activity of dimeric flavonoids 1-3 in vitro and their possible mechanism of action. Moreover, the most active flavonoid was selected for in vivo testing in a model of cutaneous leishmaniasis.

\section{Results}

\subsection{In Vitro Activity Against Leishmania Promastigotes and Cytotoxicity to Mammalian Cells}

The purified compounds from A. brachypoda were tested against different species of Leishmania, namely L. amazonensis, L. infantum and L. braziliensis. First, Leishmania promastigotes were submitted to the treatment with compounds 1-3 (Figure 1) at concentrations ranging from 0.25 to $20 \mu \mathrm{M}$ for $72 \mathrm{~h}$. Compound 1 was not active against any Leishmania species at the tested concentrations, while compounds 2 and 3 presented similar potency and were active against all three Leishmania species. $\mathrm{AMB}$, used as a positive control, showed a higher potency against promastigotes than the dimeric flavonoids assayed (Table 1).

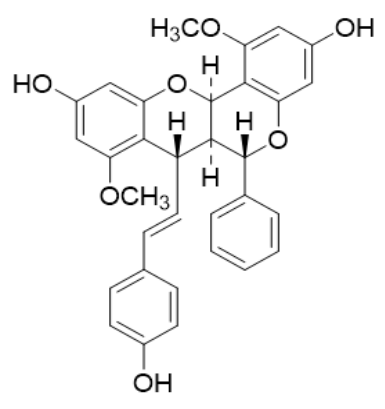

1

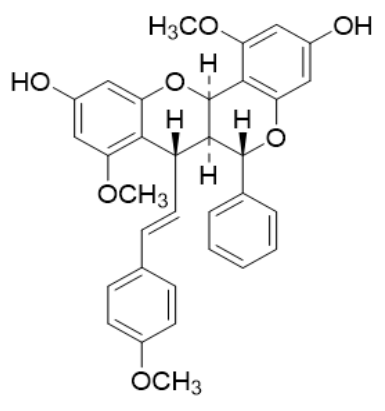

2

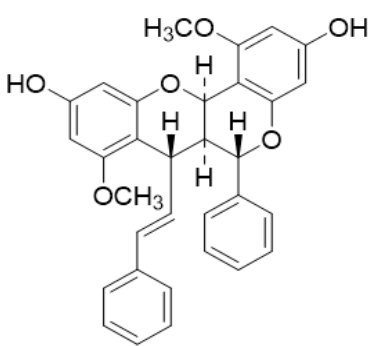

3

Figure 1. Structure of the tested compounds, Brachydin A (1), Brachydin B (2), and Brachydin C (3). 
Table 1. In vitro pharmacological activity of dimeric flavonoids.

\begin{tabular}{ccccccc}
\hline \multicolumn{3}{c}{$\mathrm{IC}_{\mathbf{5 0}}(\boldsymbol{\mu M})$ Promastigotes Leishmania sp. } & \multicolumn{3}{c}{$\mathrm{IC}_{\mathbf{5 0}}$ Amastigotes } \\
\hline Compound & L. amazonensis & L. braziliensis & L. infantum & $\mathbf{C C}_{\mathbf{5 0}} \mathbf{M} \boldsymbol{\Phi}$ & IC $_{\mathbf{5 0}}$ L. amazonensis & SI \\
\hline$(\mathbf{1})$ & $>20$ & $>20$ & $>20$ & $>20$ & $>20$ & $\mathrm{NC}$ \\
$(\mathbf{2})$ & $9.16 \pm 1$ & $7.05 \pm 1$ & $12.90 \pm 3$ & $>20$ & $2.20 \pm 0.09$ & 9.1 \\
$(\mathbf{3})$ & $10 \pm 0.80$ & $8.82 \pm 3$ & $18.36 \pm 2$ & $>20$ & $6.25 \pm 1.28$ & 3.2 \\
$\mathrm{AMB}$ & $0.14 \pm 0.01$ & 0.11 & 0.05 & $>20$ & $0.10 \pm 0.02$ & 200 \\
\hline
\end{tabular}

AMB: amphotericin B; $\mathrm{M} \Phi$ : macrophages; $\mathrm{CC}_{50}$ : cytotoxic concentration to $50 \%$ of macrophages; $\mathrm{IC}_{50}$ : cytotoxic concentration to $50 \%$ of parasites; SI: selective index $\left(\mathrm{CC}_{50} / \mathrm{IC}_{50}\right)$.

Compounds 1-3 were first tested against non-infected primary macrophages to identify the toxic profile of the compounds in mammalian cells. The $\mathrm{CC}_{50}$ of compounds 1-3 based on Alamar Blue metabolism are shown in Table 1. All dimeric flavonoids tested did not present toxicity to peritoneal macrophages at $20 \mu \mathrm{M}$ (Table 1). The high content analysis was applied to automatically quantify the nuclei number after $72 \mathrm{~h}$ of treatment. The automated quantification revealed no reduction in cell number after the treatment at $50 \mu \mathrm{M}$. On the other hand, menadione, a known cytotoxic compound [9], significantly reduced the number of macrophages at the same concentration (Figure 2). This result is in agreement with molecules containing the benzopyrano[4,3-b]benzopyran structures, as shown by previously published work [8].
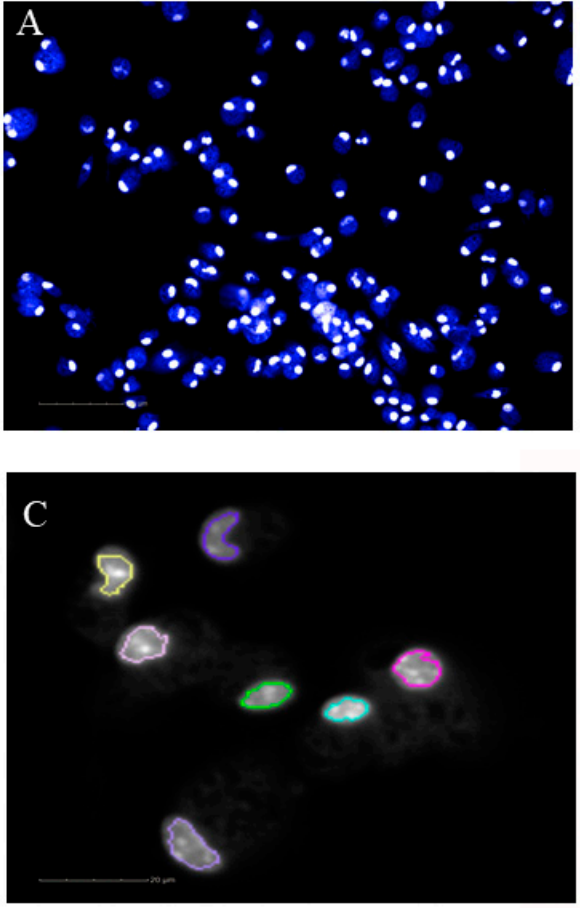

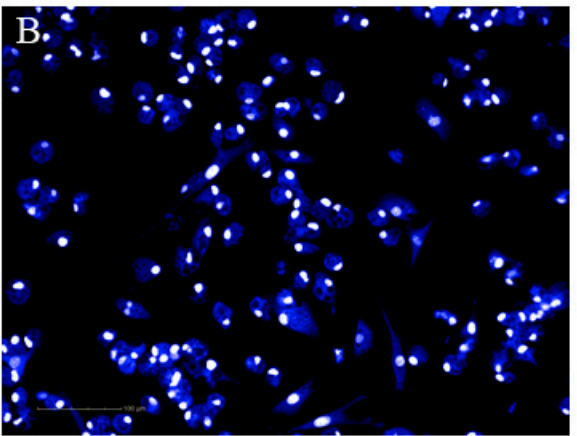

$\mathrm{D}$

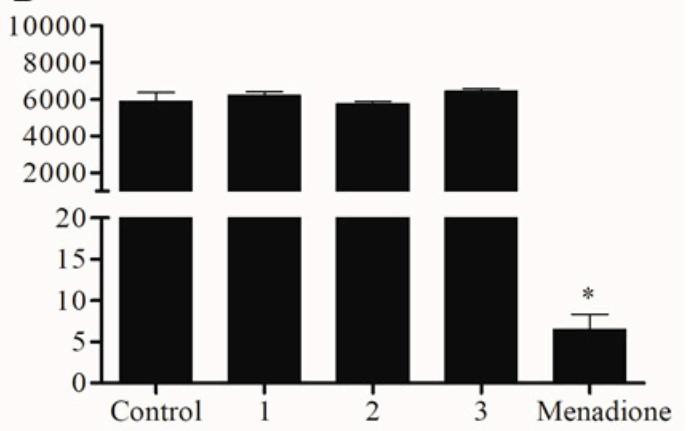

Figure 2. Automated drug toxicity assay. Macrophages from peritoneal exudate were collected from BALB/c mice. Cells were treated with compounds $1-3$ at $50 \mu \mathrm{M}$ or with menadione at $50 \mu \mathrm{M}$ during $72 \mathrm{~h}$. (A) Non-treated macrophages. (B) Macrophages treated with compound 2 at $50 \mu \mathrm{M}$ during 72 h. (C) Nuclei regions selected based on the "find nuclei" building block algorithmic from Harmony software. (D) Graph showing the nuclei number, the parameter used to quantify the number of cells after the treatment. The graph shows one experiment of two performed in quadruplicate. Bars are mean \pm standard deviation (SD). ${ }^{*} p<0.05$, one-way ANOVA analysis of variance related to untreated control. Scale bar $=100 \mu \mathrm{m}(\mathbf{A}, \mathbf{B})$ and $20 \mu \mathrm{m}(\mathbf{C})$.

\subsection{Activity Against Amastigotes of L. amazonensis}

Peritoneal exudate macrophages were infected with L. amazonensis and treated using non-toxic concentrations of dimeric flavonoids. Compound $\mathbf{1}$ was inactive against intracellular parasites, at $20 \mu \mathrm{M}$ 
(Table 1). Compounds 2 and 3 were assayed at $6 \mu \mathrm{M}$ and significantly reduced the percentage of infected peritoneal macrophages, as well as the number of amastigotes (Figure 3). It is noteworthy that compound 2 almost cleaned the infected cells at $6 \mu \mathrm{M}$ (Figure 3 ). The $\mathrm{IC}_{50}$ concentrations against amastigotes are shown in Table 1 . AMB was more active against intracellular amastigotes than the tested compounds. Based on the highest activity against intracellular parasites and the low toxicity to the host cell, compound 2 presented a higher selective index than compound 3: 9.1 and 3.2, respectively (Table 1).

A

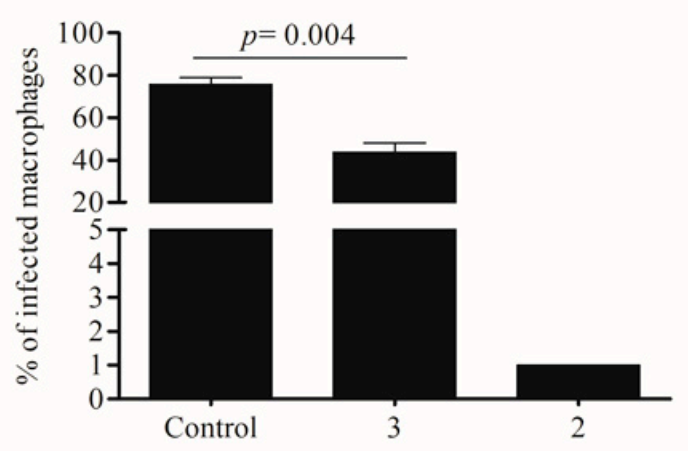

B

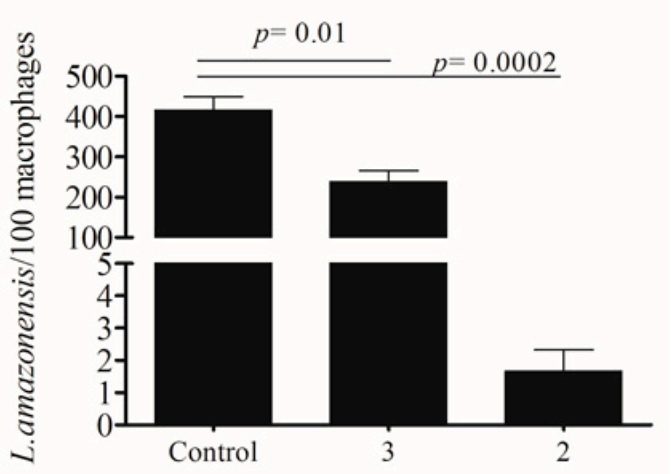

Figure 3. Effect of compounds 2 and 3 against amastigotes of L. amazonensis. Macrophages from peritoneal exudate were collected from BALB/c mice and infected with L. amazonensis promastigotes in the stationary growth phase during $6 \mathrm{~h}$. The cells were washed and incubated during $24 \mathrm{~h}$ without treatment. After this period, the macrophages were treated with the compounds at $6 \mu \mathrm{M}$ for $48 \mathrm{~h}$.

(A) Percentage of infected cells was evaluated by counting of 100 cells as well as the parasite number.

(B). $p$-value was measured by unpaired t-test compared to control group.

The automated image analysis was also applied to quantify the amastigote number after the treatment. After cell fixation and nuclei staining with Hoechst, the 96-well plates were submitted to image acquisition using the Operetta High-Content System. The cell segmentation was performed following the building blocks of image analysis created in the Hoechst 33342 reagent fluorescence channel (Figure 4). Intracellular parasites were selected in the cytoplasmic region using fluorescence intensity parameters, based on non-infected controls. AMB was used to validate the automated counting of amastigotes after treatment. Infected macrophages were treated with concentrations ranging from $0.07 \mu \mathrm{M}$ to $10 \mu \mathrm{M}$ during $72 \mathrm{~h}$. This treatment presented a concentration-response relationship, regarding the percentage of infected cells as well as the total number of amastigotes in each well (Figure $5 \mathrm{~A}, \mathrm{~B}$ ). The $\mathrm{IC}_{50}$ calculated, based on the logarithmic concentration of $\mathrm{AMB}$ and the reduction of amastigotes number (\% biological response) was 0.23 (Figure $5 \mathrm{C}$ ), similar to previously published concentrations [10].

The same protocol for image analysis was applied to quantify the biological response of compound 2, the most active dimeric flavonoid tested, as a single drug or in combination with AMB. The automated quantification of amastigotes presented an $\mathrm{IC}_{50}$ concentration equal to $2.4 \pm 0.5 \mu \mathrm{M}$ (Figure 5D). This value is similar to the $\mathrm{IC}_{50}$ concentration calculated by the manual counting of amastigotes (Table 1), validating again the automated method of parasite counting.

Combined treatment was performed using AMB and compound 2. The sum of FIC generated a value of 1.5 , corresponding to an additive effect relationship between these drugs. This value, slightly higher than the established cut-off value of 1 , indicates that there are no interactions between them $[11,12]$. 


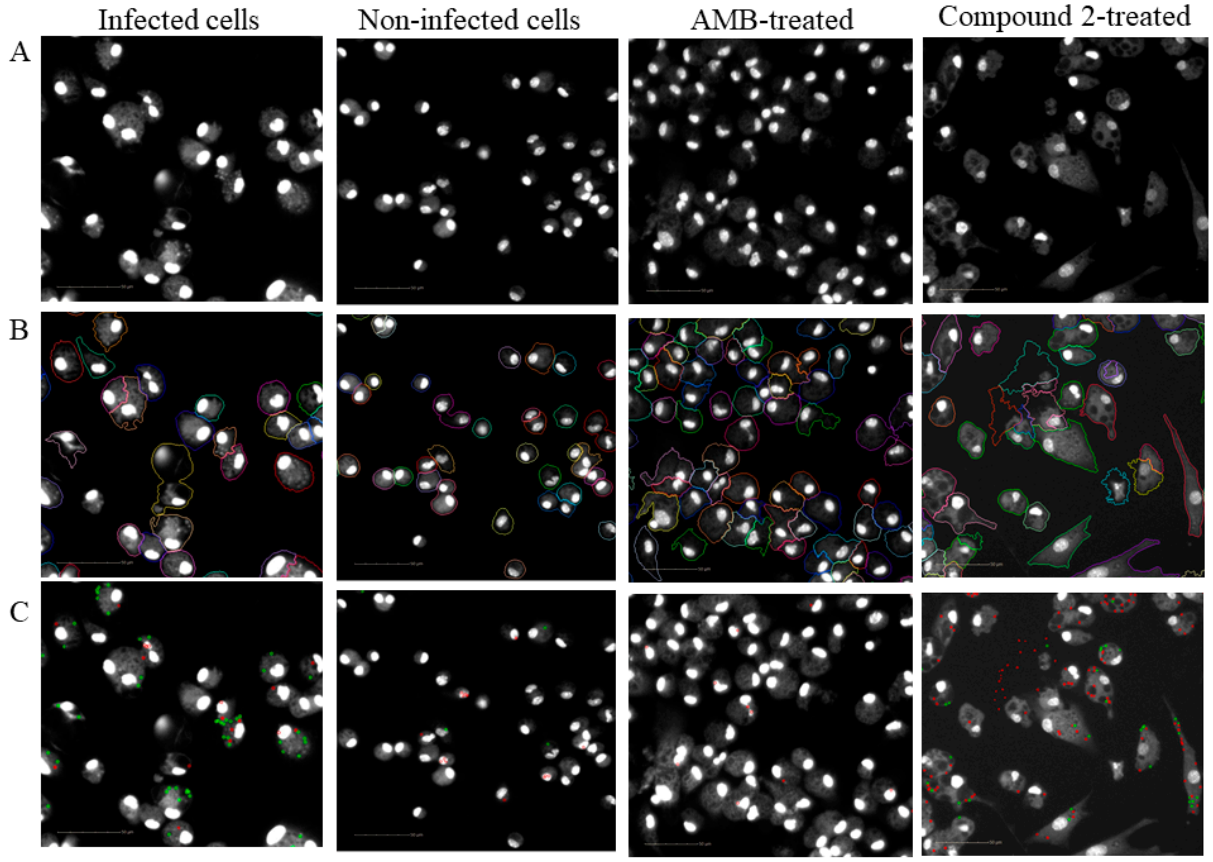

Figure 4. Image analysis process. Representative images of macrophages infected with L. amazonensis, non-infected control (mock), AMB-treated infected cell at $2 \mu \mathrm{M}$ and compound 2-treated infected cell at $10 \mu \mathrm{M}$ : (A) raw image acquired using the Hoechst channel; (B) cytoplasm segmentation based on nuclei selection using the "find cytoplasm" building block. Different colours are used to visually distinguish the cells; (C) discrimination between real parasites in the cytoplasm region (green) and non-parasite spot in the cytoplasm (red). Scale bar $=50 \mu \mathrm{m}$.
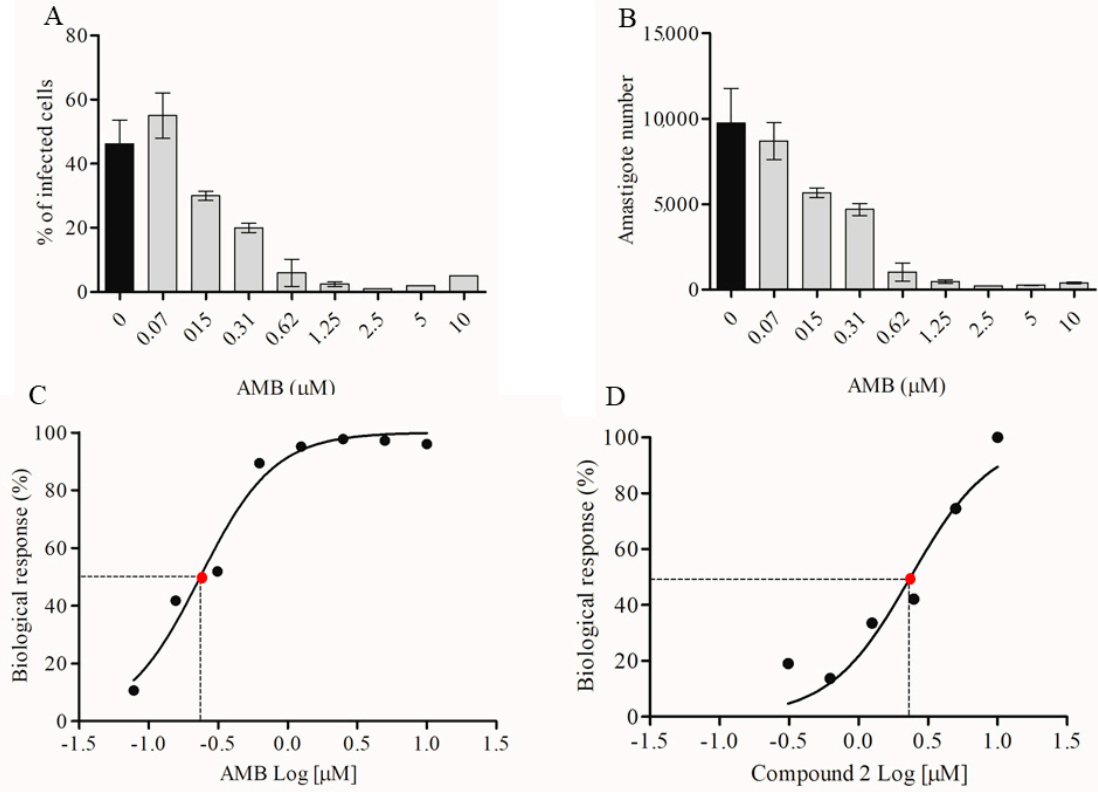

Figure 5. Automated quantification of amastigotes after treatment. (A,B) Infected cells were treated with $\mathrm{AMB}$ at different concentrations. The automated image segmentation and parasites quantification workflow were applied to determine the percentage of infection as well as the number of amastigotes. Bars represent the mean \pm SD of one representative assay performed with eight replicates. (C,D) Quantification of the biological response after the treatment with AMB and compound 2 at concentration ranging from 0.15 to $10 \mu \mathrm{M}$. The correlation coefficient (r2) is 0.97 for AMB and 0.65 for compound 2. Red dot means the logarithmic concentration related to $50 \%$ biologic response. 


\subsection{Electron Microscopy}

Transmission electron microscopy was performed in infected and treated macrophages to investigate the alterations induced by compound 2 in the intracellular amastigotes at the ultrastructural level. This assay was performed at low concentration, $6 \mu \mathrm{M}$, as well as reduced treatment time (24 and $48 \mathrm{~h}$ ). As shown above, even high concentrations such as $20 \mu \mathrm{M}$ and $50 \mu \mathrm{M}$ were not able to generate toxicity to the macrophages. Non-treated cells presented amastigotes with rounded cell shape and normal organelle morphology, such as nuclei, mitochondria, flagellar pocket and Golgi apparatus (Figure 6A,B). Treatment with compound 2 at $6 \mu \mathrm{M}$ for 24 or $48 \mathrm{~h}$ induced phenotypic alterations, such as enlargement of Golgi cisternae after $24 \mathrm{~h}$ (Figure 6C). In association with Golgi damage, the intracellular parasites presented accumulation of vesicles, characterized by a double membrane, inside the flagellar pocket (Figure 6D,E). Following treatment with compound 2 , the parasites accumulated multivesicular bodies (Figure 6F). These alterations led to an increase of intracellular vesicles and cytoplasmic disorganization, resulting in cell death (Figure 6G). Amastigotes carrying myelin-like figures were seen after treatment with compound 2 for $48 \mathrm{~h}$ (Figure $6 \mathrm{H}$ ).
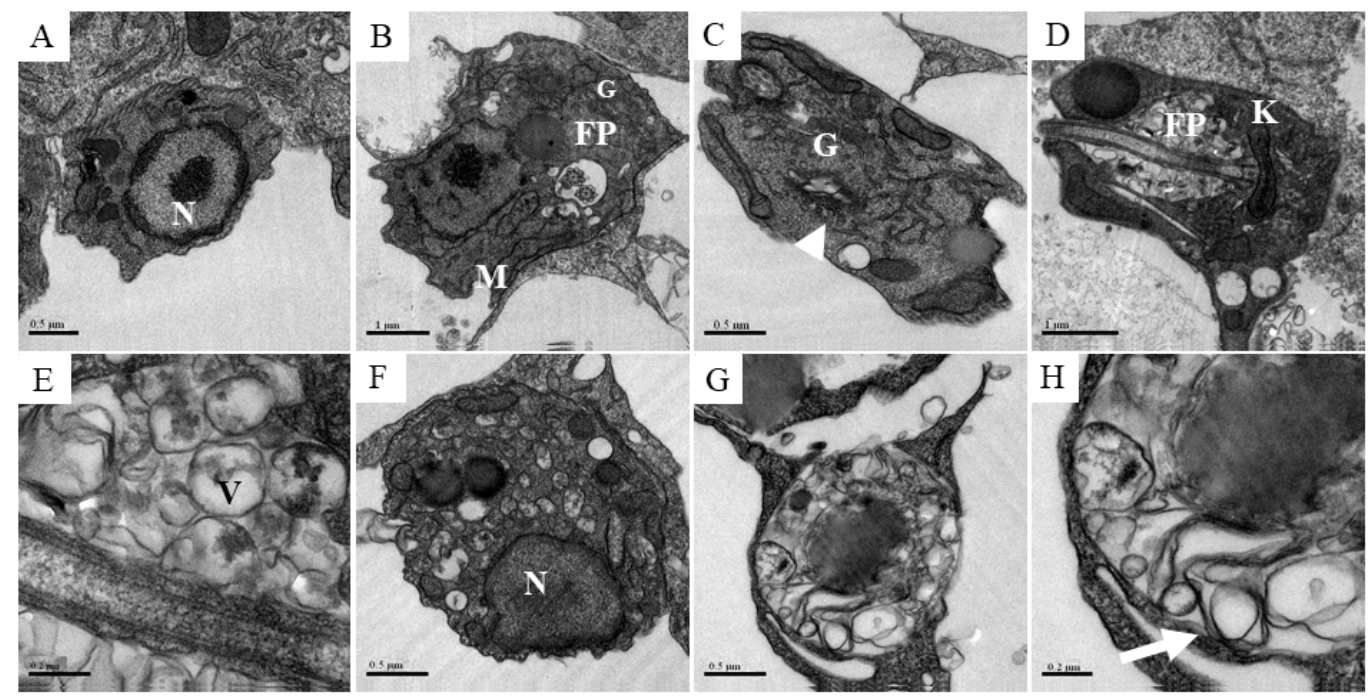

Figure 6. Ultrastructural analysis of amastigotes after the treatment with compound 2. Peritoneal macrophages from BALB/c mice were infected with stationary phase L. amazonensis promastigotes and treated with compound 2 at $6 \mu \mathrm{M}$ during 24 and $48 \mathrm{~h}$. (A,B) Control amastigotes showing normal organelles, such as nuclei, mitochondria, flagellar pocket and Golgi. (C,D) Amastigotes treated with compound 2 during $24 \mathrm{~h}$ presenting the opening of Golgi (arrowhead) and vesicle accumulation inside the flagellar pocket, respectively. (E) Zoomed image of vesicles inside the flagellar pocket highlighting the double and multiple membrane formation. $(\mathbf{F}, \mathbf{G})$ Increased accumulation of cytoplasmic vesicles in amastigotes treated with compound 2 during $48 \mathrm{~h}$. (H) Zoomed image showing a myelin-like figure in the cytoplasm of an amastigote (arrow). N, nuclei; M, mitochondria; FP, flagellar pocket; G, golgi; $\mathrm{K}$, kinetoplast; V, vacuole.

\subsection{In Vivo Infection}

Genetically susceptible BALB/c mice were infected in the ear dermis with L. amazonensis and treated by oral $(25$ and $50 \mathrm{mg} / \mathrm{kg}$ ) or topical $(1 \%)$ routes with compound 2 starting from the second week of infection. While the oral treatment with $25 \mathrm{mg} / \mathrm{kg}$ did not alter the lesion growth, treatment with $50 \mathrm{mg} / \mathrm{kg}$ of compound 2 significantly reduced the ear thickness in the second week of treatment (third week of infection). One week later, however, there was no statistically significant difference between the thickness of controls. Pentavalent antimonial (Glucantime ${ }^{\circledR}$ ), used as positive control, significantly reduced the lesion size (Figure 7A). Daily treatment with topical formulation, however, did not reduce the lesion size compared to vehicle-treated controls (Figure 7B). 

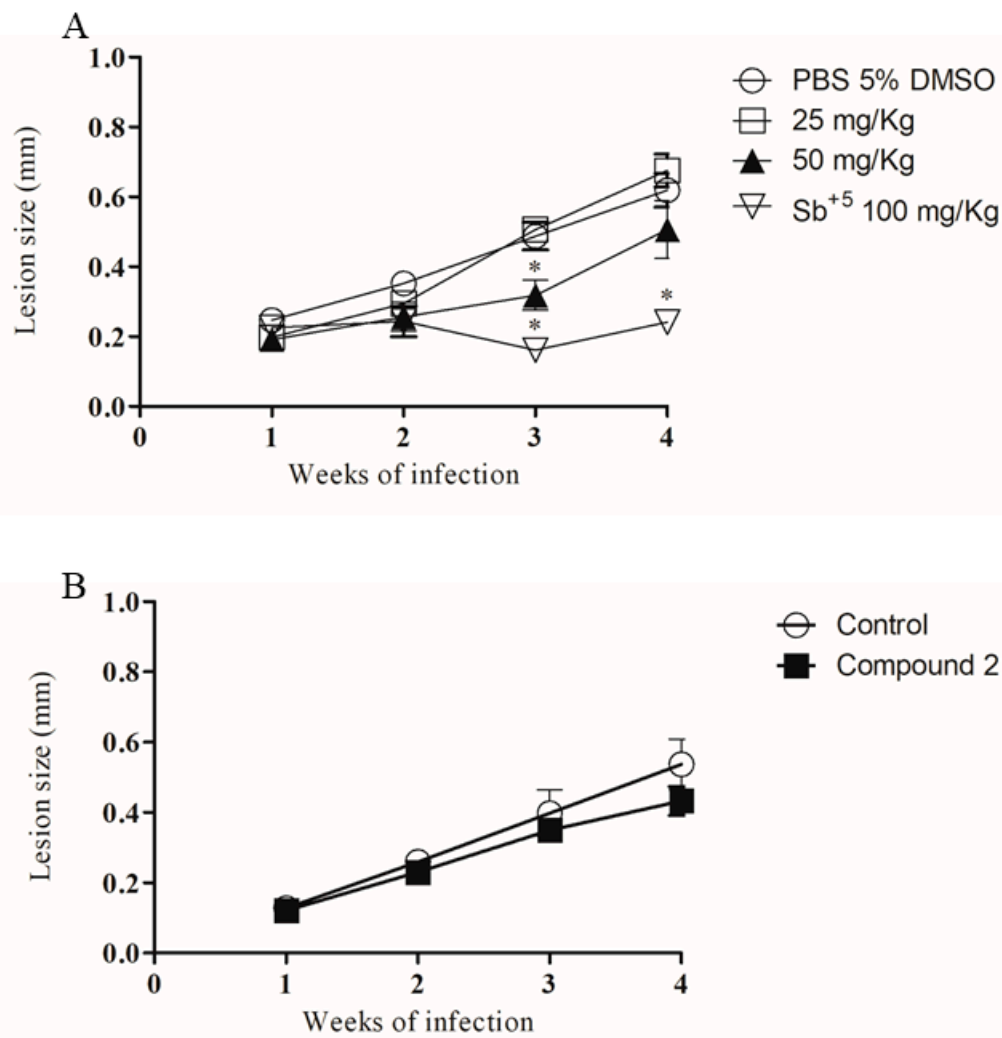

Figure 7. Pharmacological effect of compound 2 in an experimental model of cutaneous leishmaniasis. $\mathrm{BALB} / \mathrm{c}$ mice were infected with $10^{6}$ L. amazonensis promastigotes in the stationary growth phase and lesion development was monitored for four weeks. Lesion size is expressed as mean \pm SD of eight animals per group during the treatment by oral (A) or topical (B) route. ${ }^{*} p<0.05$ (two-way ANOVA, followed by Bonferroni's multiple comparison test).

\section{Discussion}

The hydroalcoholic root extract from A. brachypoda presented pharmacological activity in vitro against trypomastigotes of T. cruzi. Anti-parasitic activity was found in the dichloromethane fraction. Next, a follow up investigation revealed the presence of unusual dimeric flavonoids, from which two molecules showed biological activity against T. cruzi in vitro and in vivo [7]. Based on these findings, the dimeric flavonoids were tested against Leishmania.

Our results showed a higher activity of compound 2 against intracellular parasites. Amastigotes are the parasitic life cycle form found in mammalian hosts, responsible for the infection maintenance in the organism [13]. It is known that promastigotes differ from amastigotes not only in terms of morphology but also with respect to their metabolism. Different biochemical pathways are up or down regulated according to the life cycle parasitic stage. This distinct biology reflects different developmental programs to adapt Leishmania for intra- or extracellular survival inside the mammalian or vector host, respectively [14-16]. Therefore, the stage specific biology may influence the parasite susceptibility to chemicals $[17,18]$. Moreover, the presence of a host cell may also generate different results when compared to an assay only involving promastigotes. Compound and host features, such as permeability to the cell and parasitophorous membrane or cell metabolism, are key parameters able to give a drug more potency against intracellular amastigotes [18]. In this work, compound 2 (brachydin 2) has been shown to be more active, possibly, because the presence of the methoxyl group is necessary to improve membrane penetration. The substituents on the $C$ ring probably play a key role in the increase in lipophilicity and consequently the penetration of the compound through the host and protozoan cell membranes, since the brachydines differ only in the substituent group. The capacity of the Leishmania to evade or resist the innate immunological response is pivotal to the maintenance of 
infection. Therefore, the ability of the drug to rescue the macrophage antimicrobial response can also be more potent against infected cells $[19,20]$.

In this work, the combination of compound 2 with AMB was assayed. Based on the sum of FIC, compound 2 does not interact with AMB to improve the efficacy against intracellular parasites (synergic effect). Drug combination is an important strategy in the development of new treatments, particularly in infectious diseases. This approach can reduce the dose, time and the cost of a such pharmacological treatment, in addition to overcome the weak activity of the individual drug. Moreover, by acting through different pharmacodynamics, the combination therapy can improve treatment, as well as reduce the development of drug resistance [21].

The ultrastructural analysis of compound 2 treated amastigotes showed the ability of the compound to induce cell lesion which progressed to parasitic death. The Golgi damage associated with accumulation of vesicle inside the flagellar pocket suggests the impairment of endocytic pathways in amastigotes. Vesicle accumulation may reflect the defect in the release process or increased production and exocytosis. Vesicle traffic inside amastigotes is important for nutrient acquisition, intracellular communication, virulence and host/pathogen interaction [22,23].

Interestingly treatment with compound 2 reduced the parasitemia of T. cruzi Y strain-infected mice [7]. In that case, treatment was performed during five days at $100 \mathrm{mg} / \mathrm{kg}$ by oral route. This promising result suggests that compound 2 is absorbed by oral route and kills parasites in the blood. In contrast to the acute phase of experimental Chagas disease, during Leishmania infection, the drug needs to be distributed into internal organs, such as draining lymph nodes, spleen and liver, and towards the site of infection to exert its pharmacological activity $[24,25]$. Conceivably, the result found here may reflect the incapability of compound 2 to achieve effective concentration in the infected ear by oral route. The treatment of Leishmania-infected mice may need to be longer than three to four weeks. To avoid in vivo toxicity, the highest daily dose was reduced to $50 \mathrm{mg} / \mathrm{kg}$. The ineffectiveness of the topical treatment may also reflect the pharmacokinetics problems, in this case related to drug absorption by the skin.

The promising in vitro results of compound 2 were not reproduced during the in vivo experiments, by factors related to the drug/formulation pharmacokinetics, as discussed above, or even host-related mechanisms, such as liver metabolism. However, this work presented a novel compound with high in vitro activity against amastigotes that can be used for lead optimization and structural-activity relationship studies [26]. Our ultimate aim is to generate a highly selective drug, based on compound 2 and improve pharmacokinetic features, following high content drug screening and in vivo assays.

\section{Materials and Methods}

\subsection{Plant Material}

A. brachypoda roots were collected in April 2010 at Sant'Ana da Serra farm João Pinheiro, Minas Gerais, Brazil. The plant was identified at the ICEB of the José Badine Herbarium of the Federal University of Ouro Preto by Prof. Maria Cristina Teixeira Braga Messias. A voucher specimen (no. 17935) has been deposited at the Herbarium of the Federal University of Ouro Preto, Brazil. The plant was collected in accordance with Brazilian authorities (SISGEN N ${ }^{\circ}{ }^{\circ}$ A451DE4).

\subsection{Extraction and Isolation of Compounds Brachydin A (1), Brachydin B (2), and Brachydin C (3)}

The dimeric flavonoids 1-3 have been obtained using the same process previously described [7]. NMR and HRMS have determined the structures of the compounds. The purity of each compound was determined by UHPLC-HRMS analysis. For all compounds the purity was above $98 \%$. 


\subsection{Mice}

Female, 4 to 8-weeks-old C57BL/ 6 or BALB/c mice were obtained from the Animal Facilities of the Gonçalo Moniz Institute-FIOCRUZ (Salvador, Brazil). Animals were housed in temperature-controlled rooms $\left(22-25^{\circ} \mathrm{C}\right)$ under a 12:12 h light-dark cycle and provided with rodent diet and water ad libitum. Animals were handled according to the NIH guidelines for animal experimentation. All procedures described here had prior approval from the local animal ethics committee (approval number 018/2015).

\subsection{Parasites}

L. amazonensis (MHOM/BR88/BA-125) were routinely passed in C57BL/6 mice to maintain virulence. Parasites were isolated from the popliteal lymph node after cultivation in biphasic Novy-Nicolle-MacNeal (NNN) medium containing Schneider's insect medium (Sigma Aldrich, St. Louis, MO, USA) supplemented with 10\% fetal bovine serum (Gibco Laboratories, Waltham, MA, USA) and $50 \mu \mathrm{g} / \mathrm{mL}$ of gentamicin (Hipolabor, Belo Horizonte, Minas Gerais, Brazil) at $24^{\circ} \mathrm{C}$. The obtained promastigotes were transferred to complete Schneider's insect medium, cultivated until stationary growth and used in the following experiments. L. braziliensis (MHOM/BR88/BA-3456) and L. infantum (MHOM/BR2000/Merivaldo2) were cultivated until reaching the stationary phase in Schneider's insect medium supplemented with $10 \%$ or $20 \%$ fetal bovine serum, respectively. The virulence of both species was maintained by passages in BALB/c female mice.

\subsection{Activity of Dimeric Flavonoids Against Axenic Promastigotes of Leishmania}

Stationary phase L. amazonensis, L. braziliensis and L. infantum promastigotes were seeded in a 96-well plate at a density of $2 \times 10^{6}$ parasites $/ \mathrm{mL}$ in $200 \mu \mathrm{L}$ of complete Schneider's insect medium. Cells were treated with dimeric flavonoids at concentrations ranging from 0.25 to $20 \mu \mathrm{M}$ for $72 \mathrm{~h}$. AMB was used as positive control $(0.04$ to $3 \mu \mathrm{M})$. Promastigotes viability was measured by Alamar Blue (Invitrogen, Carlsbad, CA, USA) metabolism and colorimetric readings were performed at 570 and $600 \mathrm{~nm}$. The blank used in this assay was the medium plus Alamar Blue without parasites. The $\mathrm{IC}_{50}$ concentration was calculated based on the percent inhibition of parasite growth, related to negative controls, and accessed through concentration logarithm values followed by nonlinear regression curve fit. Analyses were performed using the GraphPad Prism version 5.01 (GraphPad Prism, San Diego, CA, USA).

\subsection{Cytotoxicity Assay}

Peritoneal exudate macrophages from BALB/c mice were isolated as previously described, after five days of thioglycolate (Sigma Aldrich) stimulation [27]. The cells $\left(5 \times 10^{4}\right.$ per well in $\left.200 \mathrm{~mL}\right)$ were cultured in 96-well plates in the presence of compounds 1-3 at concentrations ranging from 2.5 to $20 \mu \mathrm{M}$ during $48 \mathrm{~h}$ at $37^{\circ} \mathrm{C}$ in $5 \% \mathrm{CO}_{2}$. Cells were incubated with $20 \mu \mathrm{L}$ of Alamar Blue per well (Invitrogen) for an additional $24 \mathrm{~h}$. Colorimetric absorbance readings were performed at 570 and $600 \mathrm{~nm}$ and used to calculate the percentage of growth inhibition after the treatment. The blank used in this assay was the medium plus Alamar Blue without the cells. The cytotoxic concentration to 50\% of macrophages $\left(\mathrm{CC}_{50}\right)$ was calculated through non-linear regression using GraphPad Prism version 5.01.

\subsection{In Vitro Macrophage Infection with L. amazonensis}

Peritoneal exudate macrophages from BALB/c mice were obtained after five days of thioglycolate stimulation (Sigma Aldrich) and infected with L. amazonensis [27]. Cells $\left(2 \times 10^{5} / \mathrm{mL}\right)$ were plated in 24-well plates containing $13 \mathrm{~mm}$-diameter glass coverslips in Dulbecco's Modified Eagle Medium (DMEM) containing 10\% fetal bovine serum (Gibco Laboratories) and incubated overnight at $37^{\circ} \mathrm{C}$ with $5 \% \mathrm{CO}_{2}$. Macrophages were infected with stationary phase promastigotes at a ratio of 5 parasites per host cell for $6 \mathrm{~h}$ at $35^{\circ} \mathrm{C}, 5 \% \mathrm{CO}_{2}$. Each well was washed to remove free parasites, and cultures were incubated for $24 \mathrm{~h}$ under the same conditions to allow promastigote to amastigote differentiation. 
Infected cells were incubated with several concentrations of dimeric flavonoids (0.24 to $20 \mu \mathrm{M})$ or AMB $(10$ to $0.07 \mu \mathrm{M})$ during $72 \mathrm{~h}$ at $37^{\circ} \mathrm{C}, 5 \% \mathrm{CO}_{2}$. The cells were fixed with ethanol and stained with conventional haematoxylin and eosin $(\mathrm{H} \& \mathrm{E})$. The inhibitory concentration for $50 \%$ of parasites $\left(\mathrm{IC}_{50}\right)$ was calculated based on the percent reduction of amastigote number compared to negative control.

\subsection{Image Acquisition}

The infected macrophages were fixed with a paraformaldehyde $4 \%$ in phosphate buffered saline during $20 \mathrm{~min}$ at room temperature, after $72 \mathrm{~h}$ of treatment. Cells were stained with Hoechst 33342 (Thermo Fischer Scientific, Waltham, MA, USA) at $16 \mu \mathrm{M}$. Images were acquired using the Operetta High-Content System in non-confocal mode and 20X air objective, for further segmentation and quantification (Perkin Elmer, Waltham, MA, USA). Pictures from five fields per well were analysed for reliable statistics.

\subsection{Automated Image Analysis}

The images of infected cells were analyzed using the Harmony software version 3.5.2 (Perkin Elmer) using an algorithm provided by the software building blocks. Nuclei were detected using the Hoechst fluorescence channel, as well as the cytoplasm. The intracellular amastigotes were detected as spots in the cytoplasmic selected region. A mock control was used to remove the background spot detection and select the correct spots as amastigotes. Fluorescence intensity parameters, such as median, mean, maximum intensity and contrast, were applied to automatically select the amastigotes in infected cells. Nuclei detection allowed the quantification of cell number for quality control and cytotoxic evaluation while amastigote detection allowed the quantification of total number of parasites.

\subsection{Calculation of Biological Response}

The biological response of the tested compounds was determined as following: \% of biological response $=(X 1-X x / X 1-X 2) \times 100$, where $X 1$ is the lowest activity (untreated cells, maximum of parasite number), $X 2$ is the highest activity (non-infected cells) and $X x$ is the tested drug at different concentrations [28]. The percentage of biological response was determined based on the total number of amastigotes and indicates the percentage of parasite number reduction after the treatment, related to non-treated cell and corrected by the non-infected group. The $\mathrm{IC}_{50}$ was calculated using non-linear regression. Cytotoxicity was calculated based on the number of nuclei after the treatment. The percentage of cell decrease was calculated based on the untreated control. Calculations were performed using GraphPad Prism version 5.01.

\subsection{Drug Combination}

Combined treatment was performed with $\mathrm{AMB}$ at a maximum concentration of $2 \mu \mathrm{M}$. The fixed ratio combination was equal to 5 . The combination was submitted to six serial dilutions. The percentage of biological response of combined drugs was used to calculate the fraction of inhibitory concentration (FIC). The combined effect was classified based on the combination index (CI), which is the sum of FIC generated: $\mathrm{CI} \leq 0.5$ indicates synergism (drug combination can exert biological response which are more than the sum of the effect of the drugs alone); $0.5 \leq \mathrm{CI} \leq 4$ indicates additivity (no interaction) and $\mathrm{CI} \geq 2$ indicates antagonism (drug combination can exert biological response which are less than the sum of the effect of the drugs alone) [12].

\subsection{Transmission Electron Microscopy}

Peritoneal exudate macrophages obtained from BALB/c mice were plated at a density of $10^{6}$ cell per well in 6-well plate. Adhered macrophages were infected with L. amazonensis, as previously described. Compounds were added at $6 \mu \mathrm{M}$, and cultures were incubated for 24 or $48 \mathrm{~h}$ at $35^{\circ} \mathrm{C} 5 \%$ $\mathrm{CO}_{2}$. Infected and treated macrophage cultures were fixed in a solution of $2.5 \%$ glutaraldehyde, $2 \%$ 
formaldehyde and $2.5 \mathrm{mM} \mathrm{CaCl}_{2}$ in $0.1 \mathrm{M}$ sodium cacodylate buffer $\mathrm{pH} 7.2$, followed by post-fixation in $1 \%$ osmium tetroxide and $0.8 \%$ potassium ferricyanide in the same buffer. The macrophages were removed from the 6-well plate using cell scraper and the samples were submitted to acetone gradient dehydration. Finally, the material was embedded in Poly/Bed resin. Ultrathin sections were stained with uranyl acetate and lead citrate and observed under a JEM 1320 transmission electron microscope (JEOL, Tokyo, Japan).

\subsection{In Vivo Infection with L. amazonensis}

Female BALB/c mice, four to six-weeks-old, were infected in the right ear dermis with $10^{6}$ L. amazonensis promastigotes in stationary growth phase in $10 \mu \mathrm{L}$ of saline. After one week of infection, mice were treated daily by oral or topical routes during the following three weeks. The ear swelling was monitored weekly, using a digital caliper (Mitutoyo, Kanagawa, Japan) and was determined as the difference in thickness between the infected and contra-lateral uninfected ear. The control groups received saline by oral route or the water emulsifying ointment by topical route. This later formulation was composed of emulsifying cetostearyl alcohol (type A) $30 \% w / w$, liquid paraffin $20 \%$ $w / w$ and white soft paraffin $50 \% w / w$. The active compound was incorporated in the ointment as a $1 \%$ DMSO solution.

Author Contributions: Conceptualization, V.P.C.R, G.B.G., C.Q.d.R.; methodology, V.P.C.R, G.B.G., P.F., L.M., E.A.; validation, V.P.C.R, G.B.G. formal analysis, V.P.C.R, M.B.P.S.; investigation, V.P.C.R, M.B.P.S.; resources, M.B.P.S. E.F.Q., J.-L.W, E.A.; writing—original draft preparation, V.P.C.R, M.B.P.S., E.F.Q.; supervision, M.B.P.S., E.F.Q., W.V., J.-L.W., E.A.; project administration, M.B.P.S., E.F.Q., J.-L.W.; funding acquisition, M.B.P.S., E.F.Q., J.-L.W.

Funding: This research was funded by: National Council for Scientific and Technological Development (CNPq), Coordination of Improvement of Higher Level Personnel (CAPES) and Foundation for Research Support of the State of Bahia (FAPESB).

Acknowledgments: We would like to thank to Kyan James Allahdadi for the extensive English review.

Conflicts of Interest: The authors declare no conflict of interest.

\section{References}

1. Alvar, J.; Vélez, I.D.; Bern, C.; Herrero, M.; Desjeux, P.; Cano, J.; Jannin, J.; den Boer, M.; The WHO Leishmaniasis Control Team. Leishmaniasis worldwide and global estimates of its incidence. PLoS ONE 2012, 7, e35671. [CrossRef] [PubMed]

2. Croft, S.L.; Sundar, S.; Fairlamb, A.H. Drug resistance in leishmaniasis. Clin. Microbiol. Rev. 2006, 19, 111-126. [CrossRef]

3. González, B.; Suárez-Roca, H.; Bravo, A.; Salas-Auvert, R.; Avila, D. Chemical composition and biological activity of extracts from arrabidaea bilabiata. Pharm. Biol. 2000, 38, 287-290. [CrossRef]

4. Martin, F.; Hay, A.-E.; Cressend, D.; Reist, M.; Vivas, L.; Gupta, M.P.; Carrupt, P.-A.; Hostettmann, K. Antioxidant C-glucosylxanthones from the leaves of Arrabidaea patellifera. J. Nat. Prod. 2008, 71, 1887-1890. [CrossRef] [PubMed]

5. Leite, J.P.V.; Oliveira, A.B.; Lombardi, J.A.; Filho, J.D.S.; Chiari, E. Trypanocidal activity of triterpenes from Arrabidaea triplinervia and derivatives. Biol. Pharm. Bull. 2006, 29, 2307-2309. [CrossRef]

6. da Rocha, C.Q.; Vilela, F.C.; Cavalcante, G.P.; Santa-Cecília, F.V.; Santos-e-Silva, L.; dos Santos, M.H.; Giusti-Paiva, A. Anti-inflammatory and antinociceptive effects of Arrabidaea brachypoda (DC.) Bureau roots. J. Ethnopharmacol. 2011, 133, 396-401. [CrossRef]

7. da Rocha, C.Q.; Queiroz, E.F.; Meira, C.S.; Moreira, D.R.M.; Soares, M.B.P.; Marcourt, L.; Vilegas, W.; Wolfender, J.-L. Dimeric flavonoids from Arrabidaea brachypoda and assessment of their anti-Trypanosoma cruzi activity. J. Nat. Prod. 2014, 77, 1345-1350. [CrossRef]

8. Devakaram, R.; Black, D.S.; Andrews, K.T.; Fisher, G.M.; Davis, R.A.; Kumar, N. Synthesis and antimalarial evaluation of novel benzopyrano[4,3-b]benzopyran derivatives. Bioorg. Med. Chem. 2011, 19, 5199-5206. [CrossRef] 
9. Loor, G.; Kondapalli, J.; Schriewer, J.M.; Chandel, N.S.; Vanden Hoek, T.L.; Schumacker, P.T. Menadione triggers cell death through ROS-dependent mechanisms involving PARP activation without requiring apoptosis. Free Radic. Biol. Med. 2010, 49, 1925-1936. [CrossRef] [PubMed]

10. Siqueira-Neto, J.L.; Moon, S.; Jang, J.; Yang, G.; Lee, C.; Moon, H.K.; Chatelain, E.; Genovesio, A.; Cechetto, J.; Freitas-Junior, L.H. An image-based high-content screening assay for compounds targeting intracellular Leishmania donovani amastigotes in human macrophages. PLoS Negl. Trop. Dis. 2012, 6, e1671. [CrossRef]

11. Chou, T.-C.; Talalay, P. Quantitative analysis of dose-effect relationships: The combined effects of multiple drugs or enzyme inhibitors. Adv. Enzyme Regul. 1984, 22, 27-55. [CrossRef]

12. Odds, F.C. Synergy, antagonism, and what the chequerboard puts between them. J. Antimicrob. Chemother. 2003, 52, 1. [CrossRef]

13. Zulfiqar, B.; Shelper, T.B.; Avery, V.M. Leishmaniasis drug discovery: Recent progress and challenges in assay development. Drug Discov. Today 2017, 22, 1516-1531. [CrossRef] [PubMed]

14. Rosenzweig, D.; Smith, D.; Opperdoes, F.; Stern, S.; Olafson, R.W.; Zilberstein, D. Retooling Leishmania metabolism: From sand fly gut to human macrophage. FASEB J. 2008, 22, 590-602. [CrossRef]

15. Saxena, A.; Lahav, T.; Holland, N.; Aggarwal, G.; Anupama, A.; Huang, Y.; Volpin, H.; Myler, P.J.; Zilberstein, D. Analysis of the Leishmania donovani transcriptome reveals an ordered progression of transient and permanent changes in gene expression during differentiation. Mol. Biochem. Parasitol. 2007, 152, $53-65$. [CrossRef]

16. Burchmore, R.J.; Barrett, M.P. Life in vacuoles-nutrient acquisition by Leishmania amastigotes. Int. J. Parasitol. 2001, 31, 1311-1320. [CrossRef]

17. Vermeersch, M.; da Luz, R.I.; Toté, K.; Timmermans, J.-P.; Cos, P.; Maes, L. In vitro susceptibilities of Leishmania donovani promastigote and amastigote stages to antileishmanial reference drugs: Practical relevance of stage-specific differences. Antimicrob. Agents Chemother. 2009, 53, 3855-3859. [CrossRef]

18. De Muylder, G.; Ang, K.K.H.; Chen, S.; Arkin, M.R.; Engel, J.C.; McKerrow, J.H. A screen against Leishmania intracellular amastigotes: Comparison to a promastigote screen and identification of a host cell-specific hit. PLoS Negl. Trop. Dis. 2011, 5, e1253. [CrossRef]

19. Jaramillo, M.; Gomez, M.A.; Larsson, O.; Shio, M.T.; Topisirovic, I.; Contreras, I.; Luxenburg, R.; Rosenfeld, A.; Colina, R.; McMaster, R.W.; et al. Leishmania repression of host translation through mTOR cleavage is required for parasite survival and infection. Cell. Host. Microbe. 2011, 9, 331-341. [CrossRef] [PubMed]

20. Buates, S.; Matlashewski, G. Treatment of experimental leishmaniasis with the immunomodulators imiquimod and S-28463: Efficacy and mode of action. J. Infect. Dis. 1999, 179, 1485-1494. [CrossRef]

21. Zheng, W.; Sun, W.; Simeonov, A. Drug repurposing screens and synergistic drug-combinations for infectious diseases. Br. J. Pharmacol. 2018, 175, 181-191. [CrossRef] [PubMed]

22. Borges, V.M.; Vannier-Santos, M.A.; de Souza, W. Subverted transferrin trafficking in Leishmania-infected macrophages. Parasitol. Res. 1998, 84, 811-822. [CrossRef] [PubMed]

23. Silverman, J.M.; Reiner, N.E. Exosomes and other microvesicles in infection biology: Organelles with unanticipated phenotypes. Cell. Microbiol. 2011, 13, 1-9. [CrossRef] [PubMed]

24. Courret, N.; Lang, T.; Milon, G.; Antoine, J.C. Intradermal inoculations of low doses of Leishmania major and Leishmania amazonensis metacyclic promastigotes induce different immunoparasitic processes and status of protection in BALB/c mice. Int. J. Parasitol. 2003, 33, 1373-1383. [CrossRef]

25. Mears, E.R.; Modabber, F.; Don, R.; Johnson, G.E. A Review: The Current In Vivo Models for the Discovery and Utility of New Anti-leishmanial Drugs Targeting Cutaneous Leishmaniasis. PLoS Negl. Trop. Dis. 2015, 9, e0003889. [CrossRef]

26. Khare, S.; Nagle, A.S.; Biggart, A.; Lai, Y.H.; Liang, F.; Davis, L.C.; Barnes, S.W.; Mathison, C.J.N.; Myburgh, E.; Gao, M.-Y.; et al. Proteasome inhibition for treatment of leishmaniasis, Chagas disease and sleeping sickness. Nature 2016, 537, 229-233. [CrossRef]

27. Gomes, I.N.; Calabrich, A.F.d.C.; Tavares, R.d.S.; Wietzerbin, J.; de Freitas, L.A.R.; Veras, P.S.T. Differential properties of CBA/J mononuclear phagocytes recovered from an inflammatory site and probed with two different species of Leishmania. Microbes. Infect. 2003, 5, 251-260. [CrossRef] 
28. Tegazzini, D.; Díaz, R.; Aguilar, F.; Peña, I.; Presa, J.L.; Yardley, V.; Martin, J.J.; Coteron, J.M.; Croft, S.L.; Cantizani, J. A Replicative In vitro Assay for Drug Discovery against Leishmania donovani. Antimicrob. Agents Chemother. 2016, 60, 3524-3532. [CrossRef]

Sample Availability: Samples of the compounds are available from the authors.

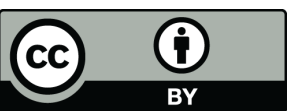

(C) 2018 by the authors. Licensee MDPI, Basel, Switzerland. This article is an open access article distributed under the terms and conditions of the Creative Commons Attribution (CC BY) license (http://creativecommons.org/licenses/by/4.0/). 